\title{
Los recursos documentales y su aporte a los servicios informativos de televisión: el caso de Televisión Española en Murcia
}

\author{
Information resources and their contribution to television news services: \\ the case of Televisión Española in Murcia
}

\author{
Vivina Asensi Artiga (1), Juan Tomás Frutos (2) y Eva Miñano Pastor (3) \\ Facultad de Comunicación y Documentación, Universidad de Murcia, 30071 Murcia (1) vasensi@um.es \\ (2) jtomas@um.es (3) Biblioteca Pública Municipal. Ayuntamiento de Lorquí, eva.m.p@alu.um.es
}

\begin{abstract}
Resumen
Análisis de las funciones del servicio de documentación de Televisión Española en Murcia, mediante el estudio del archivo, de su aporte a los informativos y de la opinión del personal de este centro territorial. Se pretende estimar el valor añadido que aporta el servicio de documentación a la realización de los informativos territoriales de TVE en Murcia; analizar la proporción de noticias que se realizan con grabaciones diarias, con documentación audiovisual y con utilización de ambos recursos, así como la tipología y soporte de las peticiones documentales, y conocer la opinión de los profesionales de TVE en Murcia sobre el servicio de documentación. Para ello, se estudió el material procedente de los fondos del archivo de TVE en Murcia; analizando los 41 informativos pertenecientes a los meses de marzo y abril de 2008, y los resultados obtenidos a partir de un cuestionario distribuido entre los trabajadores de la plantilla del Centro Territorial. El servicio de docum entación del Centro Territorial de TVE en Murcia ofrece importantes beneficios a los profesionales que allí trabajan y al propio informativo. El porcentaje de noticias que utilizan documentación audiovisual es elevado. La documentación audiovisual permite proporcionar imágenes a las noticias para las que no se dispone de grabaciones diarias y completar la información. El mayor número de peticiones al archivo corresponde a la categoría de lugares, y el uso de documentación audiovisual es más elevado en las cuatro primeras noticias del informativo. Los profesionales de TVE en Murcia defienden la potenciación del archivo.
\end{abstract}

Palabras clave: Servicios de Documentación. Documentación Audiovisual. Televisión Española en Murcia. Calidad de los informativos. Valor de la documentación.

\section{Introducción}

A menudo buscamos la importancia de algunos de los elementos que constituyen el mensaje informativo en aspectos formales o de contenido; pero no siempre reflexionamos sobre el valor que implementa y mejora la historia que se

\begin{abstract}
Analysis of the functions of the documentation service of Televisión Española in Murcia, through an analysis of the archive and its contribution to news programmes and a survey on the opinion of the staff of this regional centre. The objectives were three: estimating the added value contributed to the regional news programmes of TVE in Murcia; analysing the proportion of news items produced with audiovisual documentation using daily recordings, and, in addition, the type and format of documentary requests; and establishing the opinion of professional staff at TVE in Murcia as to the documentation service. For that, the TVE Murcia archive resources were studied; 41 news programmes from the months of March and April 2008 were analyzed; and the results obtained through a questionnaire distributed to workers on the staff of the Regional Centre were examined. The documentation service at TVE's Regional Centre in Murcia provides substantial professional benefits to the professionals working there and also to the news programs themselves. The percentage of news items employing audiovisual documentation is high. Audiovisual documentation provides images for news items for which no daily recordings exist, supplementing the information. The largest number of archive requests are related to locations; and the usage of audiovisual documentation is more substantial in the first four items of the news programme. Professional staff at TV in Murcia want the archive services to be strengthened.
\end{abstract}

Keywords: Documentary Services. Audiovisual Documentation. Televisión Española in Murcia. Quality of News Programmes. Value of documentation. RTVDoc.

quiere comunicar y que proviene, precisamente, de la documentación, de los recursos audiovisuales (en el caso de televisión) que se han ido atesorando a lo largo del tiempo. Desde esta perspectiva, valoramos también el porcentaje de ahorro de tiempo y de mejora de la calidad informativa procedente de la documentación es- 
crita, como fuente primaria de la que se obtienen los datos que se ubican en un texto noticioso.

El origen de los archivos audiovisuales se remonta a los inicios del cine y, posteriormente, al desarrollo de la televisión. A partir de la utilización de sistemas digitales, el archivo audiovisual es parte importante del activo económico de las empresas de televisión; de hecho, en las tareas propias del proceso documental incidirán, sin duda, los retos de carácter tecnológico a los que nos enfrentamos (Hidalgo, 2007).

En los inicios de Televisión Española habitualmente se usaban, en su mayoría, noticias montadas sólo con grabaciones diarias, siendo muy inferiores las noticias editadas solamente con documentación y las mixtas (con documentación y grabaciones diarias a la vez). La cuestión tecnológica era decisiva en esta situación, por la complejidad que implicaba tener una documentación acorde a las necesidades de un medio que comenzaba su andadura. En las últimas décadas, los profesionales de todos los ámbitos y categorías de lo audiovisual han visto en la documentación un instrumento para mejorar la calidad y el propio mensaje.

Los estudios realizados sobre el tema de la documentación audiovisual en las cadenas de televisión son en su mayoría generalistas. A este respecto podemos citar los trabajos relacionados con las fuentes (Caldera y Zapico, 2001; Caldera y Rodríguez, 2005; García Marco, 2005); el proceso documental (Caldera y Nuño, 2001; Hidalgo, 2003; Rodríguez, 2004; Giménez, 2007) y concretamente análisis (Nuño y Caldera, 2000; Caldera-Serrano y SánchezJiménez, 2008) y perfiles profesionales (Catalá, 2002; Hidalgo, 2005; López, 2007).

Ante los cambios que afectan a profesionales y usuarios del servicio de los archivos audiovisuales, resulta necesario el análisis en profundidad de los elementos de estos sistemas a fin de optimizar su desarrollo. A nuestro juicio, sería conveniente la realización de estudios más concretos que, sin duda, contribuirán a mejorar la calidad del mensaje. Los resultados de este trabajo, monográfico y de carácter específico, centrado en los informativos de Televisión Española (TVE) en Murcia, permitirán el conocimiento de los problemas puntuales y la aportación de posibles soluciones.

Por ello, nos hemos planteado como objetivo una investigación que, además de estudiar todos los recursos que aparecen en un informativo, ha tenido en cuenta el parecer, la opinión y los comentarios de los diversos profesionales que pertenecen al organigrama de una televi- sión. Los resultados, aunque algunos intuidos, serán claros y contundentes.

\section{El servicio de documentación del Centro Territorial de TVE en Murcia}

El Centro Territorial de TVE inició sus emisiones el 17 de Junio de 1980 y a lo largo de su historia ha atravesado diferentes etapas con vicisitudes propias de un ente público. El servicio de documentación del Centro Territorial de TVE en Murcia ofrece importantes recursos documentales a los profesionales que allí trabajan y al propio informativo que se mantiene en la actualidad. Hasta ahora se han nutrido de él los espacios informativos y los diferentes programas regionales, sin olvidar los aportes a la cadena nacional. Para comprender la riqueza de sus fondos, cabe mencionar que, si bien en la actual coyuntura la programación territorial queda reducida al informativo de las dos de la tarde y a las colaboraciones con Madrid, en 1998 se llegaron a superar las 700 horas de emisión. Conviene destacar que la colaboración con los servicios centrales es tan intensa o más que en etapas anteriores: Se envían noticias y reportajes a espacios de La 1, de La 2 y del Canal 24 horas (Tomás, 2008). Gracias a su archivo, TVE Murcia tiene una clara ventaja frente a otras cadenas locales y autonómicas de la Región, cuyos archivos, por su juventud o por falta de medios, no alcanzan el nivel de calidad y de riqueza que posee el del Centro Territorial. Este valor añadido que aporta la documentación se refleja en el producto final que es el Informativo.

\section{Material y métodos}

Para obtener la proporción de uso de la documentación en los informativos de TVE en Murcia, un centro que, por sus dimensiones y nivel de actividad no excesiva, se ha utilizado como modelo, se han estudiado muestras correspondientes a los meses de marzo y abril del año 2008, período con un total de 621 noticias. Estas noticias se han dividido en tres grupos, basándonos en el uso de documentación audiovisual, la utilización de grabaciones diarias, o bien, como es lógico, el uso de ambos recursos.

Los recursos audiovisuales se han clasificado de acuerdo con la metodología seguida por Agirreazaldegi (1996) y para conocer la opinión del personal, 25 trabajadores pertenecientes a diferentes categorías laborales, se diseñó un cuestionario para la recogida de datos mediante las entrevistas informales mantenidas con ellos y su posterior estudio. A partir de los datos obtenidos, se ha estudiado la opinión del personal de TVE en Murcia respecto a la importancia de 
la documentación, a la necesidad de un servicio de documentación con el archivo actualizado, así como a la naturaleza de las peticiones que realizan los profesionales a este servicio en cuanto al tipo de documentos solicitados y los factores que en ello influyen.

\section{La documentación en la empresa informativa}

Los periodistas de TVE consideran necesaria la documentación de y en la empresa informativa por unanimidad. El motivo de que el $76 \%$ de los trabajadores opine que la documentación es más importante en el caso de los espacios informativos, puede ser consecuencia de las peculiaridades del Centro Territorial de TVE en Murcia, en el que la programación se ciñe únicamente a la emisión del espacio informativo de las dos de la tarde y a que históricamente, aunque haya habido una programación más abundante, con magazines y otra serie de programas, éstos han tratado siempre temas de actualidad y otra serie de contenidos informativos. El continente en el mundo de la imagen es crucial y así lo ven todos los profesionales de TVE en Murcia, la mayoría con una media de quince años de trabajo en la empresa, con un conocimiento extraordinario del medio y de la sociedad en cuestión. El consumidor de televisión necesita, por sus propias características y por las peculiaridades del medio, que todo se le oferte de la manera más cómoda, entendible y creíble que sea posible. La documentación de archivo es necesaria para enmarcar el contexto de la noticia y para conferir credibilidad a la información y al procedimiento de su elaboración (Sánchez, 2007).

\subsection{La documentación escrita}

Todo parece indicar que no se tiene muy en cuenta en la confección de una noticia la información documentada escrita, considerando sólo un $16 \%$ de los trabajadores su utilidad. La documentación escrita como fuente informativa es muy importante, mejora la calidad y proporciona precisión a la información. Hay que tener en cuenta que la mayoría de los profesionales de TVE en Murcia no han pasado por la esfera de la Prensa escrita, y por ello desconocen los valores fundamentales que aporta. Esto contrasta, además, con que se tiene la creencia de que las noticias con imágenes de documentación son más representativas, que se ven más nutridas, mejores. Se observa un exceso de confianza en la imagen y aunque nadie duda de su relevancia, sí sería conveniente recurrir a la fuente informativa escrita, que, a menudo, ni se utiliza.
Tan importante como la documentación audiovisual es la documentación escrita, los documentos primarios, como fuente para recuperar, comprobar y contrastar los datos y dirigir el relato en uno $u$ otro sentido. Aunque el valor de esta documentación se haya puesto en duda por ciertos sectores de la sociedad de la información (Mattelart, 2007), coincidiendo con la llegada de las nuevas tecnologías e Internet de un manera generalizada a todos los medios y a toda la sociedad, en la actualidad es indiscutible en el campo de la información y la documentación el protagonismo de las fuentes documentales escritas, cualquiera que sea el soporte, para la transmisión del mensaje correspondiente a la noticia. Los resultados de la encuesta reflejan disparidad de criterios, dependiendo de la formación y de la actividad que realizan los encuestados. Así, el $71 \%$ de los informadores consultados opina que el porcentaje de información documentada escrita que se tiene en cuenta en la confección de una noticia oscila entre un 10 y un $50 \%$; mientras que entre el resto de personal, que corresponde a otras categorías laborales, predomina la opinión que enmarca el porcentaje de documentación escrita utilizada en menos de un $10 \%$. Prueba del escaso uso de este recurso, es el hecho de que las respuestas no son concretas. Un periodista se define por el uso de una buena documentación escrita o por consultar varias fuentes, con el fin de no incurrir en equívocos. Es verdad que se puede llegar a ese grado de comprobación por muchas vías tecnológicas, pero no se puede prescindir de un sistema de clasificación organizado por áreas temáticas para recurrir a ellas siempre que se considere necesario.

Todo parece indicar que no se tiene muy en cuenta en la confección de una noticia la información documentada escrita, considerando solo un $16 \%$ de los trabajadores su utilidad. Se observa un exceso de confianza en la imagen y aunque nadie duda de su relevancia, sí sería conveniente recurrir a la fuente informativa escrita que, a menudo, ni se utiliza.

\subsection{Imágenes de archivo}

Por la encuesta realizada, compuesta de veinte preguntas, contestadas por los veinticinco profesionales de TVE en Murcia, se saca la conclusión de que muy pocas noticias se realizan exclusivamente con documentación audiovisual del mismo día, ya que casi siempre se acompaña con alguna imagen de archivo. El archivo es, pues, un elemento imprescindible en la confección de las noticias para enriquecer la noticia y el reportaje y mejorar la transmisión del mensaje. 
El verano es la época del año en que más se recurre al archivo documental, siendo muy valorado por todos los profesionales que trabajan en TVE. Durante los meses de julio y agosto, hay menos personal para cubrir las noticias, menos información y menos medios, y la documentación de archivo se convierte en un instrumento indispensable para la cobertura de los informativos. La falta de actividad política y la menor actividad económica propician que en el informativo pueda incluirse un mayor número de noticias y vivencias para las que no es indispensable la actualidad inmediata. En los Boletines y espacios informativos disminuye el ritmo de actividad.

\section{Actualización del archivo}

Por otra parte y pese a la importancia que se da al archivo, en determinadas etapas de la confección del informativo, los profesionales de TVE en Murcia (y los periodistas sobre todo) creen que el archivo no siempre está actualizado como debería, valorando la necesidad de una futura potenciación. Ante la pregunta acerca de la actualización, sólo se tiene en cuenta esporádicamente y por carencia de recursos mínimos esenciales.

La falta de recursos es una constante en todas las empresas periodísticas. No es una excepción el ámbito televisivo o audiovisual y el problema de dotación de recursos humanos en estos servicios existe desde su creación (Hidalgo, 2005). Pero, si el archivo no se mantiene actualizado, es difícil que pueda rentabilizar su valor añadido.

En los Servicios informativos se recurre mucho a la documentación de todo género y formulación para complementar los datos y para mejorar la calidad de la presentación de las noticias, informes y reportajes, haciéndolos mucho más atractivos y sugerentes.

\section{Análisis de las peticiones solicitadas al archivo}

En los datos sobre las peticiones de archivo analizadas, podemos observar que durante el periodo estudiado, marzo y abril, lo que más se solicitó del archivo fueron imágenes que hacían referencia a localizaciones de lugares y a conceptos concretos. Asimismo, las grabaciones diarias, con un claro concepto de lo contemporáneo y de la actualidad, suelen ser implementadas con archivo en la mayoría de los supuestos. En este aspecto cabe destacar las secciones de cultura y deportes, que, en su mayor parte, utilizan grabaciones realizadas a diario, con escaso uso de documentación audiovisual de archivo. Esto, por otro lado, depende de los períodos de tiempo a que se aplique el estudio, como ya hemos visto que sucede en los meses estivales, en que se recurre a noticias culturales y deportivas apelando al archivo disponible.

En otras secciones como la de sociedad, se equipara el uso de documentación audiovisual y la utilización de grabaciones diarias (puesto que se usa mucha información del día a día y otra documentación grabada con anterioridad para anclar noticias o referenciar lo que se narra). En el área de economía, se usa en gran parte documentación audiovisual, quedando relegadas las grabaciones audiovisuales diarias para momentos concretos como las crisis y recesiones económicas. Esta aseveración es relativa: cuando se cuenta con más recursos se elaboran más noticias y se recurre a todos los elementos de los que se pueda disponer, siempre bajo la premisa de adecuar costes con beneficios.

Respecto al número de peticiones correspondientes a los diferentes días de la semana, el lunes es el día de menor actividad en este aspecto y el viernes, cuando más peticiones se realizan. El informativo de los lunes (jornada del deporte por antonomasia) ofrece también información correspondiente al fin de semana; sin embargo, el viernes, considerado como la antesala de lo que va a ocurrir y el resumen de la semana, necesita más imágenes de archivo.

\subsection{Categorías y composición documental de la noticia.}

El número de noticias que recurren a la documentación audiovisual total o parcialmente alcanza un porcentaje del $41 \%$. Las noticias que utilizan imágenes de archivo lo hacen, con exclusividad de éstas, o acompañándolas de grabaciones diarias. Los porcentajes varían en función de las noticias y de la época del año, así como de los recursos empleados o a los que se puede recurrir.

Entre los grupos más numerosos nos encontramos en este período con el de las noticias montadas con documentación: se cuantificaron un total de 150. Después están las noticias que usaron ambos recursos, un total de 104 noticias. Estas cifras indican el rigor de su elaboración.

El porcentaje más amplio (el 59\%) lo ocupan las noticias montadas exclusivamente con grabaciones diarias. Este resultado responde a que el medio televisivo es dinámico, y trata de mostrar la realidad donde y como acontece, sin renunciar a la actualidad y la inmediatez. 
La categoría de documentación audiovisual más solicitada es la de lugar, seguida de concepto y, en tercer lugar por animal-cosa-fenómeno natural. El resto de categorías son inferiores al $50 \%$, aunque suponen unas cifras destacables en cada caso. En el registro de peticiones, no consta ningún documento de la categoría obra, quizá porque la cultura no ocupa un lugar destacado o porque se muestra esta sección con imágenes de la misma jornada y no con acopios de recursos anteriores. Las noticias de sociedad, de sucesos, de ciencia, de avances, etc. suelen tener mucha presencia y notoriedad.

Otro elemento muy importante es la graduación de las noticias. El uso de documentación audiovisual es más elevado en las cuatro primeras noticias del informativo, que son las más importantes en contenido e información (al menos a efectos de edición).

De todos estos datos se deduce que la documentación audiovisual se utiliza para proporcionar imágenes destinadas a cubrir e ilustrar las noticias de las que no se han obtenido grabaciones del día. Cuando el editor de un informativo considera que una noticia hay que darla, aunque no se haya podido ir al lugar donde se ha producido, se usa el archivo para contarla; si la imagen no es suficiente o no resulta adecuada, se recurre a una edición limitada de documentación de archivo que leen en directo los presentadores.

\section{Conclusiones.}

- El uso de documentación de archivo mejora la calidad de los informativos y la recepción del mensaje por el público al que va destinado.

- Las peticiones al archivo varían en función de la categoría, día de la semana, graduación de la noticia y época del año.

- Los profesionales de TVE en Murcia son conscientes del valor que aporta la documentación audiovisual de archivo a los informativos territoriales, y defienden el servicio de documentación, su mejora y su potenciación.

- Consideramos que este servicio tiene un importante futuro en los medios de comunicación, en vista de la actitud de los profesionales que nos han permitido realizar este trabajo con sus opiniones y comentarios.

\section{Referencias}

Agirreazaldegi Berriozabal, Teresa (1996). El uso de la documentación audiovisual en los programás informativos diarios de televisión. Leioa (Bizkaia): Universidad del País Vasco, 1996.
Caldera Serrano, Jorge; Nuño Moral, María Victoria (2001). Participación de las unidades de documentación televisivas en la creación del producto audiovisual en programas informativos. // Scire. 7:1 (Enero-Junio 2001) 153-162.

Caldera Serrano, Jorge; Rodríguez Rodríguez, Esther (2005). Propuesta de un sistema de información documental para las televisiones locales. // Anales de Documentación. 8 (2005) 21-36.

Caldera-Serrano, Jorge; Sánchez-Jiménez, Rodrigo (2008). Ontología para el control y recuperación de información onomástica en televisión. // El profesional de la información. 17:1 (Enero-Febrero 2008) 86-91.

Caldera Serrano, Jorge; Zapico Alonso, Felipe (2001). Principales fuentes de información audiovisual en las televisiones estatales. // Anales de Documentación 4 (2001) 39-50.

Catalá i Freixa, Montserrat (2002). Els professionals dels centres de documentació audiovisual. // Item 32 (Setembre-Desembre 2002) 17-26.

García Marco, Francisco Javier (2005). Documentación digital en los medios de comunicación y publicidad: análisis y experiencias. // Scire 11:2 (Septiembre-Diciembre 2005) 9-16.

Giménez Rayo, Mabel (2007). Documentación audiovisual de Televisión: la selección del material. Gijón: Trea, 2007.

Hidalgo Goyanes, Paloma (2003). La selección de documentos audiovisuales en televisión: la selección en TVE. // Documentación de las Ciencias de la Información. 26 (2003) 233-260.

Hidalgo Goyanes, Paloma (2005). La documentación audiovisual de las televisiones. La problemática actual y el reto de la digitalización. // Documentación de las Ciencias de la Información 28 (2005) 159-171.

López Vidales, Nereida (2007). Gestión de contenidos audiovisuales en la televisión de hoy. // Signo y pensamiento XXVI:50 (Enero-Junio 2007) 160-173.

Mattelart, Armand (2007). Historia de la sociedad de la información. Barcelona: Paidos, 2007.

Nuño Moral, María Victoria; Caldera Serrano, Jorge (2000). Criterios de Selección de imágenes en los archivos de televisión. // Revista General de Información y Documentación. 10:2 (2000) 13-24.

Rodríguez Bravo, Blanca (2004). El documento audiovisual en las emisoras de televisión: selección, conservación y tratamiento. // Biblios. 5:20 (Octubre-Diciembre 2004) 29-39.

Sánchez Illán, Juan Carlos (2007). Praxis profesional y regulación jurídica del uso de las fuentes informativas. // Farias Batlle, Pedro (dir). Informe anual de la profesión periodística 2007. Madrid: Asociación de la Prensa de Madrid, 2007. 37-42.

Tomás Frutos, Juan: 25 años de historia de TVE en Murcia (2009). // Campus digit@l. http://www.um.es/campus digital/(2009-28-04) (14-05-2009). 